\title{
Molecular Phylogenetic Analysis, Trichothecene Chemotype Patterns, and Variation in Aggressiveness of Fusarium Isolates Causing Head Blight in Wheat
}

Ali Malihipour and Jeannie Gilbert, Cereal Research Centre, Agriculture and Agri-Food Canada, Winnipeg, MB R3T 2M9, Canada; Michele Piercey-Normore, Department of Biological Sciences, University of Manitoba, Winnipeg, MB R3T 2N2, Canada; and Sylvie Cloutier, Cereal Research Centre, Agriculture and Agri-Food Canada, Winnipeg, MB R3T 2M9, Canada

\begin{abstract}
Malihipour, A., Gilbert, J., Piercey-Normore, M., and Cloutier, S. 2012. Molecular phylogenetic analysis, trichothecene chemotype patterns, and variation in aggressiveness of Fusarium isolates causing head blight in wheat. Plant Dis. 96:1016-1025.

Certain Fusarium species cause Fusarium head blight (FHB) in wheat and other small grains. Differences in characteristics of the pathogen species/isolates used in breeding programs may affect reaction of host genotypes, leading to erroneous results. To clarify differences among Fusarium isolates from different geographical zones, the phylogenetic, chemotypic, and pathogenic abilities of 58 isolates collected from three wheat-producing countries (Canada, Mexico, and Iran) were investigated. Phylogenetic relationships among the isolates were characterized using the Tri101 gene sequence. All Canadian and Iranian isolates clustered in one group and were identified as $F$. graminearum lineage 7 ( $=F$. graminearum sensu stricto) within the $F$. graminearum $(F g)$ clade. The isolates from Mexico were identified as either $F$. graminearum lineage 3 (=Fusarium boothii) within the Fg clade or Fusarium

crookwellense. A polymerase chain reaction assay based on the Tri12 gene identified three trichothecene chemotypes of 15-ADON, 3ADON, and NIV, with 15-ADON being the most common. All $F$. boothii isolates from Mexico were of the 15-ADON chemotype, while all $F$. crookwellense isolates were determined to be NIV producers. While we did not find the NIV chemotype among the Canadian isolates, $25.6 \%$ of the Iranian isolates were determined to be NIV producers. High level of variation in aggressiveness was also observed among and within the species tested: $F$. graminearum sensu stricto isolates were the most aggressive, followed by those of $F$. boothii, and lastly by $F$. crookwellense. The differences observed among the isolates may explain why wheat lines/cultivars demonstrate different reactions to FHB in different geographical zones.
\end{abstract}

Fusarium head blight (FHB) is a destructive and economically important disease of wheat, barley, and other small grains throughout the world caused by certain Fusarium species. Fusarium graminearum Schwabe is the dominant and most widespread pathogen causing the disease (38). In addition to reducing grain yield and quality, FHB may result in grain contaminated with mycotoxins harmful to humans and animals $(5,54,67)$. The most common mycotoxins produced by $F$. graminearum are trichothecenes such as deoxynivalenol (DON), 3-acetyldeoxynivalenol (3-ADON), 15acetyldeoxynivalenol (15-ADON), and nivalenol (NIV), as well as an estrogenic mycotoxin, zearalenone (ZEA) $(1,5,46,47,54,67)$.

Historically, two naturally occurring and morphologically distinct populations within $F$. graminearum known as group 1 and group 2 were described based on inability or ability of cultures to form perithecia, respectively $(20,56,57)$. Subsequent analysis based on both morphological characteristics and DNA sequence data indicated that group 1 and group 2 were phylogenetically distinct. Therefore, a new name, Fusarium pseudograminearum O'Donnell $\& \mathrm{~T}$. Aoki, was assigned to group 1 , while the name $F$. graminearum was maintained for group $2(3,4)$. Later, using the genealogical concordance phylogenetic species recognition (GCPSR) approach and phylogenetic analysis of sequences of nuclear genes such as translation elongation factor $(E F-1 \alpha), \beta$-tubulin $(T U B)$, and trichothecene 3-O-acetyltransferase (Tri101) from isolates of $F$. graminearum collected from around the world, O'Donnell et al.

Corresponding author: J. Gilbert, E-mail: jeannie.gilbert@agr.gc.ca

* The $\boldsymbol{e}$-Xtra logo stands for "electronic extra" and indicates that Figure 1 appears in color online.

Accepted for publication 9 February 2012.

http://dx.doi.org/10.1094/PDIS-10-11-0866-RE

This article is in the public domain and not copyrightable. It may be freely reprinted with customary crediting of the source. The American Phytopathological Society, 2012.
(51) detected seven phylogenetically distinct and biogeographically structured lineages. The $F$. graminearum species was characterized as the $F$. graminearum or $F g$ clade, and the lineages were designated as species (51). Using more isolates of $F$. graminearum, six additional lineages (=species) were later discovered $(52,53,61,73,75)$. Therefore, the previously known single species of $F$. graminearum is now considered to be a species complex consisting of at least 13 monophyletic species. These species have different geographic distributions, differ in production of trichothecenes, and may differ in their ability to cause disease on particular crops $(15,51,53)$. The species detected within the $F g$ clade have been formally named, and the use of new species names is recommended by O'Donnell et al. (53). The name $F$. graminearum sensu stricto has been retained for lineage 7 , the principal causal agent of FHB in wheat and barley in many parts of the world (53).

Fusarium species produce trichothecenes, which are divided into two broad categories based on the presence (B-trichothecenes) or absence (A-trichothecenes) of a keto group at the C-8 position of the trichothecene ring (68). All members of the $F g$ clade are Btrichothecene producers (73). Miller et al. (45) described two strain-specific chemotypes of DON and NIV within the $F g$ clade and the related species. The DON chemotype produces DON and/or its acetylated derivatives, and NIV chemotype produces NIV and/or its diacetylated derivatives. The DON chemotype is subdivided into two chemotypes of 3-ADON (DON and 3-ADON producers) and 15-ADON (DON and 15-ADON producers). Specific primers have been designed from the sequences of genes such as trichothecene 15-O-acetyltransferase (Tri3), trichothecene 4- $O$-acetyltransferase (Tri7), and trichothecene efflux pump (Tri12) to use in chemotype determination $(29,34,35,73)$.

Aggressiveness is an attribute of a pathogen originally defined by Vanderplank (70) as the quantity of disease induced by a pathogenic isolate on a susceptible host. The aggressiveness of $F$. graminearum isolates depends on their DON-producing capacity $(40,42)$. DON-non-producing isolates of $F$. graminearum caused a low level of disease severity in plants $(16,17)$. Bai et al. (7) con- 
cluded that the DON-non-producing isolates still could infect wheat spikes but could not spread beyond the initial infection site, suggesting that DON is an aggressiveness factor rather than a pathogenicity factor. There are also several reports indicating that DON-producing isolates are more aggressive than NIV-producing isolates $(15,25,42)$. High variation in aggressiveness has been found among $F$. graminearum isolates from different geographical regions $(8,24,39,42,44)$.

There is evidence that FHB-resistant wheat lines/cultivars tested in one region do not consistently give a resistant reaction in other geographical zones, e.g., Mexico versus Canada (J. Gilbert, personal communication). This difference may be attributed to pathogen profile, environmental conditions, and/or the interaction of both. An understanding of genetic profile and diversity of the pathogen may provide insights into its pathological and epidemiological potential, which may lead to an improvement in our strategies for control of the pathogen and management of the disease(s) it causes. The objectives of this study were: (i) to elucidate the phylogenetic relationships among Fusarium isolates collected from Canada, Mexico, and Iran based on Tri101 gene sequencing data, (ii) to determine the trichothecene chemotypes of the isolates based on Tril2 gene fragments, (iii) to assess the variation in aggressiveness among the isolates, and (iv) to determine if there is an association between phylogenetic properties and chemotype patterns with aggressiveness.

\section{Materials and Methods}

Fusarium isolates. A total of 58 Fusarium isolates from Canada, Mexico, and Iran were used in this study (Table 1). Isolates 1 to 13 were obtained from the Canadian Collection of Fungal Cultures (DAOM), Ottawa, Ontario, Canada. Isolates 14 to 20 were obtained from Cereal Research Centre (CRC), Winnipeg, Manitoba, Canada (J. Gilbert, personal communication). Isolates 21 to 35 were obtained from the International Maize and Wheat Improvement Centre (CIMMYT), Mexico, D.F., Mexico. Isolates 36 to 58 were isolated from FHB-infected wheat spikes collected from wheat fields in Iran. The isolates were chosen to provide a representative sample from Fusarium-prone areas in Canada, Mexico, and Iran. Most isolates of the pathogen originated from wheat, but there were also some isolates from barley and maize. Following single-sporing on water agar (WA), pure cultures of the isolates were grown on potato dextrose agar (PDA) and carnation leaf agar (CLA) under standard conditions for growth and sporulation, respectively, and the isolates were identified using cultural and morphological characteristics (49).

For phylogenetic analysis, the sequencing data of the Tri101 gene of the following reference isolates representing 11 species within the $\mathrm{Fg}$ clade were downloaded from GenBank and used along with the experimental isolates: NRRL 28585 (Fusarium

Table 1. Identification code, host, geographic origin, and year of collection of Fusarium isolates used to study phylogenetic analysis, trichothecene chemotypes, and variation in aggressiveness

\begin{tabular}{|c|c|c|c|c|}
\hline Serial number ${ }^{a}$ & Identification code & Host & Geographic origin & Year \\
\hline 1 & DAOM 170785 & Maize & Ottawa, Ontario, Canada & 1998 \\
\hline $2-5$ & $\begin{array}{l}\text { DAOM 177406, DAOM 177408, DAOM } 177409 \text {, } \\
\text { DAOM } 178148\end{array}$ & Wheat & Chatham, Ontario, Canada & 1998 \\
\hline 6 & DAOM 178149 & Barley & Petrolia, Ontario, Canada & 1998 \\
\hline $7-10$ & $\begin{array}{l}\text { DAOM } 180376, \text { DAOM 180377, DAOM } 180378, \\
\text { DAOM } 180379\end{array}$ & Maize & Ottawa, Ontario, Canada & 1998 \\
\hline $11-12$ & DAOM 192130, DAOM 192131 & Wheat & St. Jean, Manitoba, Canada & 1998 \\
\hline 13 & DAOM 213295 & Wheat & Burdett, Alberta, Canada & 1998 \\
\hline 14 & EMMB 19/03 & Wheat & Plum Coulee, Manitoba, Canada & 2003 \\
\hline 15 & J \& R SL 12 & Wheat & Swan Lake, Manitoba, Canada & 1996 \\
\hline 16 & MSDS $3 / 03$ & Wheat & Beausejour, Manitoba, Canada & 2003 \\
\hline 17 & $40 / 04$ & Wheat & Somerset, Manitoba, Canada & 2004 \\
\hline 18 & $71 / 04$ & Wheat & Gretna, Manitoba, Canada & 2004 \\
\hline 19 & 98/04 & Wheat & Anola, Manitoba, Canada & 2004 \\
\hline 20 & $136 / 04$ & Wheat & Elkhorn, Manitoba, Canada & 2004 \\
\hline $21-27$ & CM-1, CM-2, CM-3, CM-4, CM-5, CM-6, CM-7 & Wheat & Toluca, Edo de México, México & 1995 \\
\hline 28 & CM-8 & Wheat & El Tigre, Jalisco, México & 1997 \\
\hline 29 & CM-9 & Wheat & Jesús María, Jalisco, México & 1997 \\
\hline $30-33$ & CM-10, CM-11, CM-12, CM-13 & Wheat & Tepatitlan, Jalisco, México & 1997 \\
\hline $34-35$ & CM-14, CM-15 & Wheat & Patzcuaro, Michoacan, México & 1997 \\
\hline $36-38$ & IR-1, IR-2, IR-3 & Wheat & Sari, Mazandaran, Iran & 2005 \\
\hline $39-42$ & IR-4, IR-5, IR-6A, IR-6B & Wheat & Behshahr, Mazandaran, Iran & 2005 \\
\hline $43-47$ & IR-7A, IR-7B, IR-8, IR-9A, IR-9B & Wheat & Aliabad, Golestan, Iran & 2005 \\
\hline $48-49$ & IR-10, IR-12 & Wheat & Azadshahr, Golestan, Iran & 2005 \\
\hline $50-58$ & $\begin{array}{l}\text { IR-13, IR-14, IR-16, IR-18A, IR-18B, IR-21, IR-23, } \\
\text { IR-24A, IR-24B }\end{array}$ & Wheat & Moghan, Ardabil, Iran & 2005 \\
\hline 59 & NRRL 28585 & Herbaceous vine & Brazil & Unknown \\
\hline 60 & NRRL 28436 & Sweet potato & New Caledonia & Unknown \\
\hline 61 & NRRL 29105 & Maize ear & Kaski, Nepal & Unknown \\
\hline 62 & NRRL 26754 & Acacia mearnsii & South Africa & Unknown \\
\hline 63 & NRRL 26156 & Wheat & Shanghai, China & Unknown \\
\hline 64 & NRRL 28063 & Maize stalk & Michigan, USA & Unknown \\
\hline 65 & NRRL 29306 & Maize & New Zealand & Unknown \\
\hline 66 & NRRL 29148 & Grape ivy & Pennsylvania, USA & Unknown \\
\hline 67 & NRRL 31238 & Unknown & Unknown & Unknown \\
\hline 68 & NRRL 36905 & Wheat & Minnesota, USA & Unknown \\
\hline 69 & NRRL 37605 & Wheat & Ipolydamásd, Hungary & Unknown \\
\hline
\end{tabular}

a Isolates 1 to 13 were obtained from Canadian Collection of Fungal Cultures (DAOM), Ottawa, Ontario, Canada, isolates 14 to 20 from Cereal Research Centre (CRC), Winnipeg, Manitoba, Canada, and isolates 21 to 35 from the International Maize and Wheat Improvement Centre (CIMMYT), Mexico, D.F., Mexico. Isolates 36 to 58 were isolated from Fusarium head blight (FHB)-infected wheat spikes collected from Iran. Sequences for isolates 1 to 58 were deposited in the GenBank database under accession numbers JF911426 to JF911483. Isolates 59 to 65 representing seven species within the $F g$ clade were received from USDA/ARS Culture Collection (NRRL, Peoria, IL) to use as reference isolates in chemotype determination and aggressiveness tests. For sequencing purposes, sequences of the Tri101 gene for isolates 59 to 69 representing 11 species within the $F g$ clade were downloaded from GenBank to use as references. Accession numbers of isolates 59 to 69 were AF212586, AF212582, AF212593, AF212595, AF212599, AF212605, AY225882, AF212589, AY452813, DQ452409, and DQ452412, respectively. 
austroamericanum T. Aoki, Kistler, Geiser et O'Donnell), NRRL 28436 (Fusarium meridionale T. Aoki, Kistler, Geiser et O'Donnell), NRRL 29105 (Fusarium boothii O'Donnell, T. Aoki, Kistler et Geiser), NRRL 26754 (Fusarium acaciae-mearnsii O'Donnell, T. Aoki, Kistler et Geiser), NRRL 26156 (Fusarium asiaticum O'Donnell, T. Aoki, Kistler et Geiser), NRRL 28063 ( $F$. graminearum s.s.), NRRL 29306 (Fusarium cortaderiae O'Donnell, T. Aoki, Kistler et Geiser), NRRL 29148 (Fusarium mesoamericanum T. Aoki, Kistler, Geiser et O'Donnell), NRRL 31238 (Fusarium brasilicum T. Aoki, Kistler, Geiser et O’Donnell), 36905 (Fusarium gerlachii T. Aoki, Starkey, Gale, Kistler et O'Donnell), and 37605 (Fusarium vorosii B. Tóth, Varga, Starkey, O'Donnell, Suga et T. Aoki) (Table 1). Sequences of one $F$. pseudograminearum isolate (NRRL 28338) were also used as the outgroup in the phylogenetic analysis.

Mycelium production and DNA extraction. Mycelial disks of Fusarium isolates cultured on PDA were transferred to $125-\mathrm{ml}$ flasks containing $60 \mathrm{ml}$ of yeast-malt broth culture medium $(0.3 \%$ yeast extract, $0.3 \%$ malt extract, $0.5 \%$ peptone, and $2 \%$ dextrose) and grown at $25^{\circ} \mathrm{C}$ on a rotary shaker $(200 \mathrm{rpm})$ for 3 to 4 days (50). The mycelium was harvested as follows: (i) mycelium suspension was poured into 50-ml centrifuge tubes, centrifuged at $3,500 \times g$ at $25^{\circ} \mathrm{C}$ for $10 \mathrm{~min}$ in an Allegra 6R centrifuge (Beckman Coulter, Brea, CA), and the supernatant discarded, (ii) $10 \mathrm{ml}$ of sterile distilled water was added to the mycelium pellet, (iii) the mixture was centrifuged for another $10 \mathrm{~min}$ and the supernatant again discarded, (iv) the mycelium was blotted briefly between sterile paper towels, and (v) the harvested mycelium was lyophilized for 2 days and stored for further use. DNA was extracted using the modified CTAB miniprep method (23). DNA samples were quantified by fluorometry using Hoechst 33258 stain and diluted to $10 \mathrm{ng} / \mu \mathrm{l}$ to use in polymerase chain reaction (PCR), by adding appropriate amounts of $0.1 \times \mathrm{TE}$ buffer.

DNA amplification and sequencing. The Tril01 gene was amplified with primers AT1 and AT2 (Table 2). The PCR reaction mixture typically contained $1 \times$ PCR buffer (Invitrogen, Carlsbad, $\mathrm{CA}$ ), $2 \mathrm{mM} \mathrm{MgSO}$ (Invitrogen), $0.2 \mathrm{mM}$ of each dNTP (Invitrogen), $0.3 \mathrm{pmol} / \mu \mathrm{l}$ of each primer (Invitrogen), $0.4 \mathrm{ng} / \mu \mathrm{l} \mathrm{BSA}, 0.02$

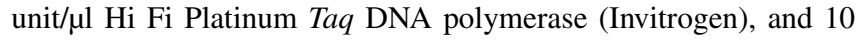
ng DNA in a reaction volume of $49 \mu \mathrm{l}$. PCR products were amplified in a PTC-100 thermal cycler (MJ Research, Waltham, MA) with the following program: (i) an initial denaturing step of 2 min at $94^{\circ} \mathrm{C}$, (ii) 35 cycles of $15 \mathrm{~s}$ at $94^{\circ} \mathrm{C}$ for DNA denaturation, $45 \mathrm{~s}$ at $60^{\circ} \mathrm{C}$ for primer annealing, and $1 \mathrm{~min}$ at $68^{\circ} \mathrm{C}$ for primer extension, (iii) a final extension of $10 \mathrm{~min}$ at $68^{\circ} \mathrm{C}$, and (iv) program held at $15^{\circ} \mathrm{C}$. Aliquots of the PCR products were loaded on $1 \%$ agarose gel to check the amplification of fragments for Tril01.

Following purification of the amplified DNA with a MultiScreen PCR plate (Millipore Corporation, Billerica, MA), cycle sequencing was conducted in a PTC-100 thermal cycler (Applied Biosys- tems, Foster City, CA) with BigDye Terminator v3.1 Cycle Sequencing Kit (Applied Biosystems) using the following program: (i) an initial denaturing step of $5 \mathrm{~min}$ at $92^{\circ} \mathrm{C}$, (ii) 60 cycles of $10 \mathrm{~s}$ at $92^{\circ} \mathrm{C}$ for DNA denaturation, $5 \mathrm{~s}$ at $55^{\circ} \mathrm{C}$ for primer annealing, and $4 \mathrm{~min}$ at $60^{\circ} \mathrm{C}$ for primer extension, (iii) a final extension of 10 min at $60^{\circ} \mathrm{C}$, and (iv) program held at $4^{\circ} \mathrm{C}$. Amplicons were sequenced with seven additional primers (Table 2) to ensure adequate coverage of all nucleotides in both directions. All sequencing reaction mixtures were run on an ABI PRISM 3100 Genetic Analyzer (Applied Biosystems) according to the manufacturer's instructions.

Phylogenetic analysis. DNA sequences were processed using PHRED (18) and assembled with CAP3 (28) as implemented in an internal data pipeline called SOOMOS v0.6 (T. Banks, personal communication). Multiple sequence alignments were accomplished using MEGA 4 (64). The sequences obtained in this study were deposited in the GenBank databases under accession numbers JF911426 to JF911483.

Phylogenetic analysis was conducted using PAUP* v. $4.0 \mathrm{~b} 10$ to estimate the genetic diversity and evolutionary relationships of the isolates from the aligned sequences (63). Maximum parsimony (MP) searches were conducted using the heuristic search option with 1,000 random addition sequences and the tree bisectionreconnection (TBR) method of branch swapping. Bootstrap analysis was performed with 500 pseudoreplicates (19), and values greater than 50 were reported on the phylogenetic tree.

Determination of trichothecene chemotypes. Trichothecene chemotypes were determined by multiplex PCR assays based on the Tril2 gene. The primers used for the amplification of the Tril2 gene included $12 \mathrm{CON}, 12 \mathrm{NF}, 12-15 \mathrm{~F}$, and 12-3F (Table 2). PCR was performed in 10- $\mu$ l volume with the following reaction mixture: 1× GeneAmp PCR buffer II (Applied Biosystems, Foster City, CA), $2 \mathrm{mM} \mathrm{MgCl}$ (Applied Biosystems), $0.16 \mathrm{mM}$ of each dNTP (Invitrogen), $0.2 \mu \mathrm{mol} / \mu \mathrm{l}$ of each primer (Invitrogen), 0.04 unit/ $\mu$ l AmpliTaq DNA polymerase (Applied Biosystems), and 20 ng DNA. PCR was conducted in a PTC-200 thermal cycler (MJ Research, Waltham, MA) with the following program: (i) an initial step of 2 min at $94^{\circ} \mathrm{C}$, (ii) 30 cycles of $30 \mathrm{~s}$ at $94^{\circ} \mathrm{C}, 30 \mathrm{~s}$ at $52^{\circ} \mathrm{C}$, and $1 \mathrm{~min}$ at $72^{\circ} \mathrm{C}$, (iii) a final extension of $7 \mathrm{~min}$ at $72^{\circ} \mathrm{C}$, and (iv) program held at $15^{\circ} \mathrm{C}$. PCR products were resolved on $1.2 \%$ (wt/vol) agarose gel and scored relative to a 100-bp DNA size ladder (Invitrogen).

Aggressiveness tests and statistical analysis. Fusarium isolates were individually inoculated on the susceptible wheat cultivar Roblin to measure disease spread within the spikes (disease severity) as an indication of the isolate's aggressiveness. Plants were grown in plastic pots $\left(16 \times 13 \times 13 \mathrm{~cm}^{3}\right)$ containing Sunshine Mix \#4 Aggregate Plus soil (Sun Gro Horticulture Canada Ltd., Seba Beach, AB, Canada) in the greenhouse, and fertilized with NPK (20:20:20) all-purpose fertilizer (Plant-Prod, Brampton, ON, Canada) weekly. Conditions in the greenhouse were kept at 15 to

Table 2. List of primers used for the Tri101 gene amplification and sequencing and trichothecene chemotype determination in Fusarium isolates

\begin{tabular}{llc}
\hline Primer name & Sequence & Forward/reverse \\
\hline $\begin{array}{l}\text { Tri101 gene amplification and sequencing } \\
\text { PCR primers: }\end{array}$ & Reference \\
AT1 & AAAATGGCTTTCAAGATACAGC & Forward \\
AT2 & C(A/G)TA(C/T)TGCGC(A/G)TA(A/G)TTGGTCCA & Reverse \\
Sequencing primers: & TTGATGCTCGACCGGCAATGG & 51 \\
AT3 & GTTGTGGTAGGTCATGTTTTG & Forward \\
AT4 & ATCCATAGCACCGTGCTGTCC & Reverse \\
AT6 & GACGTACCTGCACAACAAC & Reverse \\
F140 & AGAGTCTTGGTAGCAGCATC & Forward \\
F158 & CGGAGGTCTTTCACTACAAC & Forward \\
F171 & GTCAGGGATACGTTGGACT & Forward \\
R184 & & Reverse \\
Trichothecene chemotype determination & & 51 \\
$12 \mathrm{CON}$ & CATGAGCATGGTGATGTC & Reverse \\
$12 \mathrm{NF}$ & TCTCCTCGTTGATCTGG & Forward \\
$12-15 \mathrm{~F}$ & TACAGCGGTCGCAACTTC & Forward \\
$12-3 \mathrm{~F}$ & CTTTGGCAAGCCCGTGCA & Forward \\
\hline
\end{tabular}


$20^{\circ} \mathrm{C}$ and a photoperiod of $16 \mathrm{~h}$ was used to get an excessive number of tillers and good head types. The experimental layout was a randomized complete block design with three replicates (pots). Plants were inoculated with macroconidia of Fusarium isolates when each spike reached $50 \%$ anthesis. Using a micropipette, $10 \mu$ of inoculum $\left(5 \times 10^{4}\right.$ macroconidia/ml $)$ was injected into a single floret in a spikelet positioned $1 / 3$ from the top of the spike, and the inoculated spikes were covered with glassine bags

\begin{tabular}{|l|}
\hline Gene $=$ Tri 101 \\
Length $=1350 \mathrm{bp}$ \\
1 of 303 trees \\
123 steps \\
$\mathrm{CI}=0.94$ \\
$\mathrm{RI}=0.98$ \\
\hline
\end{tabular}

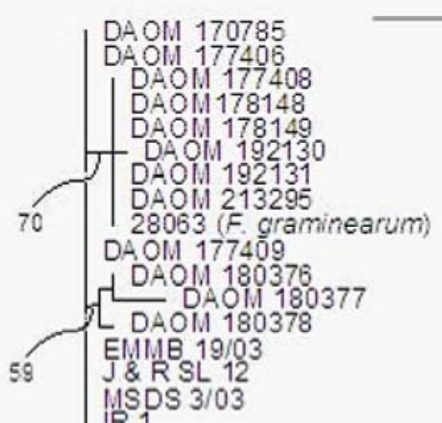

IR-2

IR-4

IR-5

IR-6B

IR-7A

R-7B

IR- 9 A

IR-9A

然-10

IR-12

IR-13

IR-18A

IR-18B

IR-23

IR-24A

IR-24

DAOIM 180379

40,04

$98 / 04$

$136 / 04$

IR-14

IR-16

26156 ( $F$. asiaticum) 36905 (F cerlachio

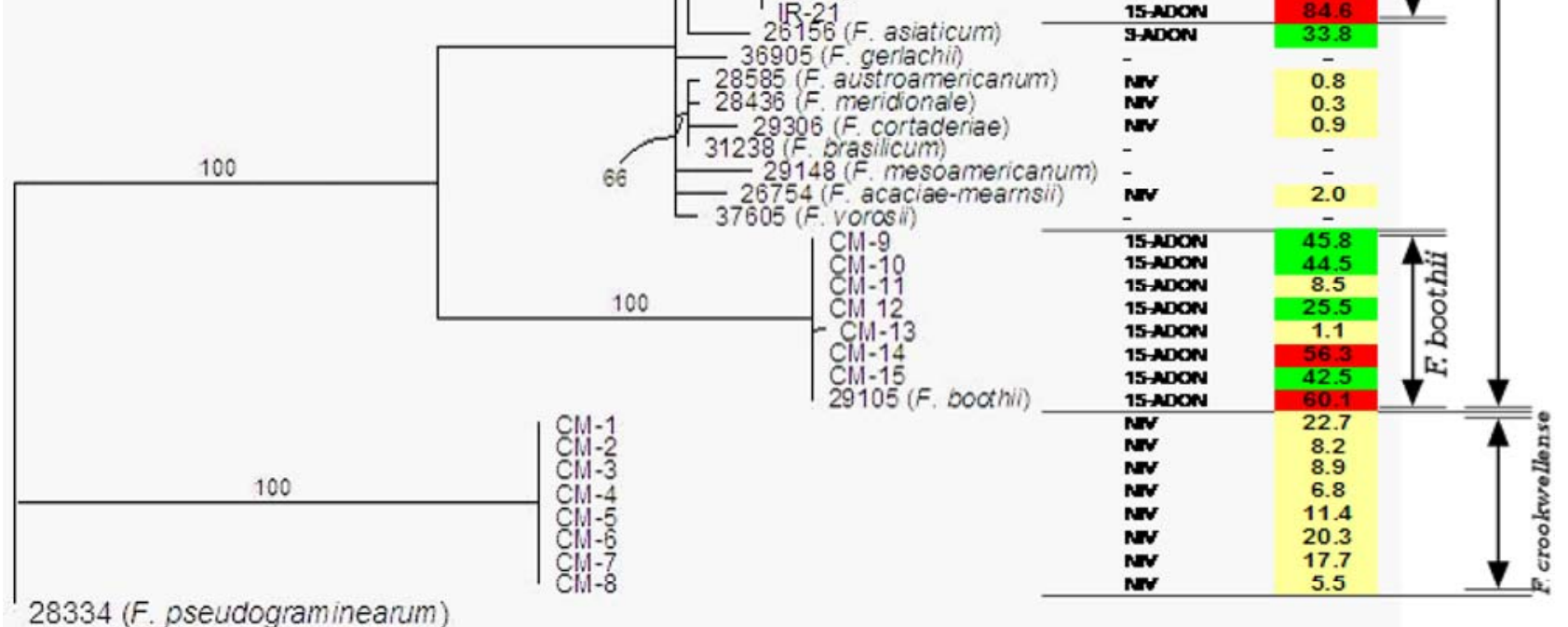

28334 (F. pseudogramineanum)

- 1 change

Fig. 1. One of 303 most-parsimonious phylogram trees generated from the Tri101 gene sequencing data using PAUP* v. $4.0 \mathrm{~b} 10$ along with chemotypes and aggressiveness values of Fusarium isolates. The isolate 28334 (F. pseudograminearum) was used to root the tree. Bootstrap values of $\geq 50 \%$ from 500 parsimony replications are shown above the internodes. Values for consistency index $(\mathrm{Cl})$ and retention index $(\mathrm{RI})$ are indicated in the top left box. Light gray $=0.0-25 \%$ (weakly aggressive), gray $=25.1-50.0 \%$ (moderately aggressive), and black $=50.1-100 \%$ (highly aggressive). Disease severity values are back-transformed from least squares means of arcsine-transformed data. 
(Seedburo Equipment Co., Chicago, IL) for $48 \mathrm{~h}$ to provide constant high humidity. Three replications (pots) and at least four spikes per replication were used for inoculation by each isolate. Plants were retained in the greenhouse under temperatures of 20 to $28^{\circ} \mathrm{C}$ and a photoperiod of $16 \mathrm{~h}$ to develop disease symptoms. Disease severity was rated as the percentage of diseased spikelets per spike 21 days after inoculation. Average percent diseased spikelet was calculated for each pot, and percentage data were arcsinetransformed prior to analysis. SAS 9.2 (SAS Institute Inc., Raleigh, NC) was used for data analysis and to compare disease severity.

\section{Results}

Identification of Fusarium isolates. All Canadian and seven out of 15 isolates received from CIMMYT, Mexico were identified as $F$. graminearum based on cultural and morphological characteristics (49). The rest of the isolates from Mexico were determined to be Fusarium crookwellense Burgess, Nelson and Toussoun (synonym: Fusarium cerealis (Cook) Scc.). A total of 23 isolates were obtained from the infected wheat samples from Iran which also were identified as $F$. graminearum.

Molecular phylogenetic analysis. The length of the Tri101 gene used to make the sequence data set in this study was 1,350 nucleotides. Results of maximum parsimony analysis showed 1,236 constant nucleotides, 65 parsimony-uninformative variable nucleotides, and 49 parsimony-informative nucleotides in the sequences. The analysis produced 303 most-parsimonious trees at 123 steps long, with consistency index (CI) and retention index (RI) of 0.94 and 0.98 , respectively. The tree reported here is a phylogram as shown in Figure 1.

Analyses of the sequence alignment of the isolates including the experimental and the reference isolates detected two distinct clades (Fig. 1). All Canadian, Iranian, and seven Mexican isolates along with the 11 reference isolates of the $F g$ clade clustered together ( $F g$ clade), while the remaining eight isolates from Mexico formed a different cluster; both clusters had a bootstrap (BP) value of
$100 \%$. Within the $F g$ clade cluster, Canadian and Iranian isolates formed a distinct cluster along with the $F$. graminearum s.s. with $90 \%$ BP. The seven isolates from Mexico clustered with the $F$. boothii reference isolate with $100 \%$ BP. Sequencing data from the present study support isolates of $F$. graminearum s.s. and $F$. boothii being separate species. The remaining eight Mexican isolates $(F$. crookwellense) formed a cluster different from the $F g$ clade based on phylogenetic analysis of DNA sequences. There was polymorphism among the isolates clustered with $F$. graminearum s.s., and subgroups with BP values of 70 and $59 \%$ were detected within the cluster (Fig. 1).

Trichothecene chemotypes. The PCR assay based on Tri12 gene produced amplicons of approximately 840, 670, and $410 \mathrm{bp}$ corresponding with NIV, 15-ADON, and 3-ADON chemotypes, respectively (61) (Fig. 2). The majority of the isolates tested $(46.6 \%)$ were of the 15 -ADON chemotype, followed by NIV (32.8\%) and 3-ADON (20.7\%) (Fig. 1 and Table 3). Our results showed that $46.5,27.9$, and $25.6 \%$ of the isolates of $F$. graminearum s.s. were 15-ADON, 3-ADON, and NIV producers, respectively. However, all isolates of $F$. boothii and F. crookwellense were determined to be 15-ADON and NIV chemotypes, respectively (Fig. 1 and Table 3).

No NIV chemotype was detected among $F$. graminearum s.s. isolates from Canada, while the majority of the isolates received from Iran were of the NIV chemotype (Fig. 1 and Table 1). The majority of the isolates collected across Canada before 1998 were of the 15-ADON chemotype, while more recently collected isolates (after 2004) were identified as 3-ADON producers. Among the Iranian isolates, all three chemotypes were detected in the northern parts of the country (Sari, Behshahar, Aliabad, and Azadshahr), while 15-ADON was the only chemotype detected among the isolates collected from the northwestern region, Moghan (Fig. 1 and Table 1).

Aggressiveness. Three Fusarium isolates, namely IR-4, IR-6A, and IR-8, failed to sporulate and were not tested for aggressive-

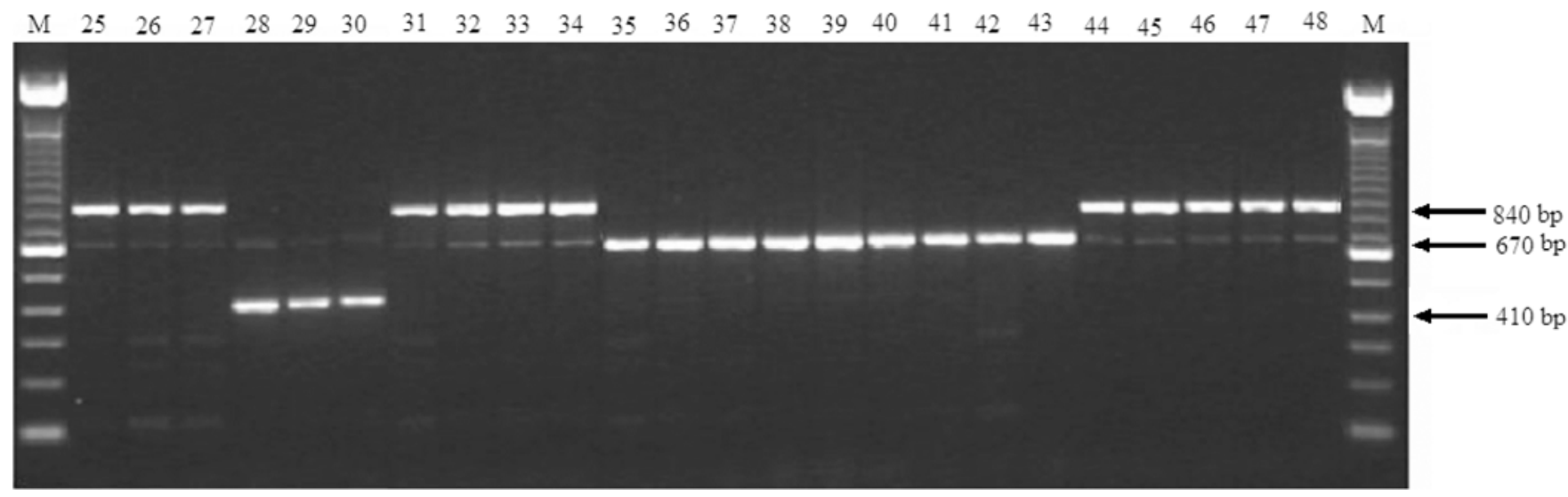

Fig. 2. Amplification products of Tri12 gene for Fusarium isolates produced by multiplex polymerase chain reaction using the primers $12 \mathrm{CON}, 12 \mathrm{NF}$, 12-15F, and 12-3F Amplification fragments of 840,670 , and 410 bp correspond with NIV, 15-ADON, and 3-ADON chemotypes, respectively. Lane M represents a 100-bp ladder (Invitrogen), and lanes 25-48 represent the following Fusarium isolates: IR-5, IR-6A, IR-6B, IR-7A, IR-7B, IR-8, IR-9A, IR-9B, IR-10, IR-12, IR-13, IR-14, IR-16, IR-18A, IR-18B, IR-21, IR-23, IR-24A, IR-24B, CM-1, CM-2, CM-3, CM-4, and CM-5.

Table 3. Distribution of trichothecene chemotypes among Fusarium isolates collected from Canada, Mexico, and Iran based on Tri12 gene

\begin{tabular}{|c|c|c|c|}
\hline \multirow[b]{2}{*}{ Fusarium species } & \multicolumn{3}{|c|}{ Chemotypes } \\
\hline & NIV & 15-ADON & 3-ADON \\
\hline F. graminearum sensu stricto (Canada) & 0 & 11 & 9 \\
\hline F. graminearum sensu stricto (Iran) & 11 & 9 & 3 \\
\hline Subtotal ( $F$. graminearum sensu stricto isolates) & $11(25.6 \%)$ & $20(46.5 \%)$ & $12(27.9 \%)$ \\
\hline F. boothii (Mexico) & 0 & 7 & 0 \\
\hline F. crookwellense (Mexico) & 8 & 0 & 0 \\
\hline Total (all isolates) & $19(32.8 \%)$ & $27(46.6 \%)$ & $12(20.7 \%)$ \\
\hline
\end{tabular}

a Trichothecene chemotypes were determined by amplification of Tri12 gene using a multiplex polymerase chain reaction conducted by $12 \mathrm{CON}, 12 \mathrm{NF}, 12-$ $15 \mathrm{~F}$, and $12-3 \mathrm{~F}$ primers. 
ness. All other isolates infected the susceptible cultivar Roblin and produced disease symptoms in a range of 0.4 to $100 \%$ based on percent infected spikelets (disease severity) (Fig. 1). Significant differences in disease severity were observed among the Fusarium isolates, evidence of differences in aggressiveness.

The pathogen isolates produced significantly different levels of disease severity according to the geographical origin of the isolates (Fig. 3). As shown in Figure 3, mean disease severities produced by Fusarium isolates from Canada and Iran were high and similar as opposed to those of the Mexican isolates. Variation in aggressiveness among the pathogen isolates was also different according to geographical zones. The highest variation in aggressiveness was observed among the Canadian isolates with disease severity ranging from 0.4 to $100 \%$, and the least variation among the Mexican isolates with disease severity in the range of 1.1 to $56.3 \%$. The range of disease severity among Iranian isolates was from 23.7 to $100 \%$. The frequency of isolates with disease severity greater than $50.0 \%$ was higher than that of isolates with disease severity lower than $50.0 \%$ (Fig. 1).

High variation in aggressiveness was observed among the phylogenetically determined Fusarium species in the Fg clade (Fig. 4). Mean disease severity among the isolates of $F$. graminearum s.s. was $78.6 \%$, while it was $28.8 \%$ among the isolates of F. boothii. Therefore, mean disease severity of $F$. graminearum s.s. isolates was more than twice that of $F$. boothii isolates. Isolates of $F$. crookwellense, which is not a species within the $F$. graminearum clade, had a mean disease severity of $12.0 \%$. Therefore, a strong association between Fusarium species and aggressiveness was observed, i.e., three species of $F$. graminearum, F. boothii, and $F$.

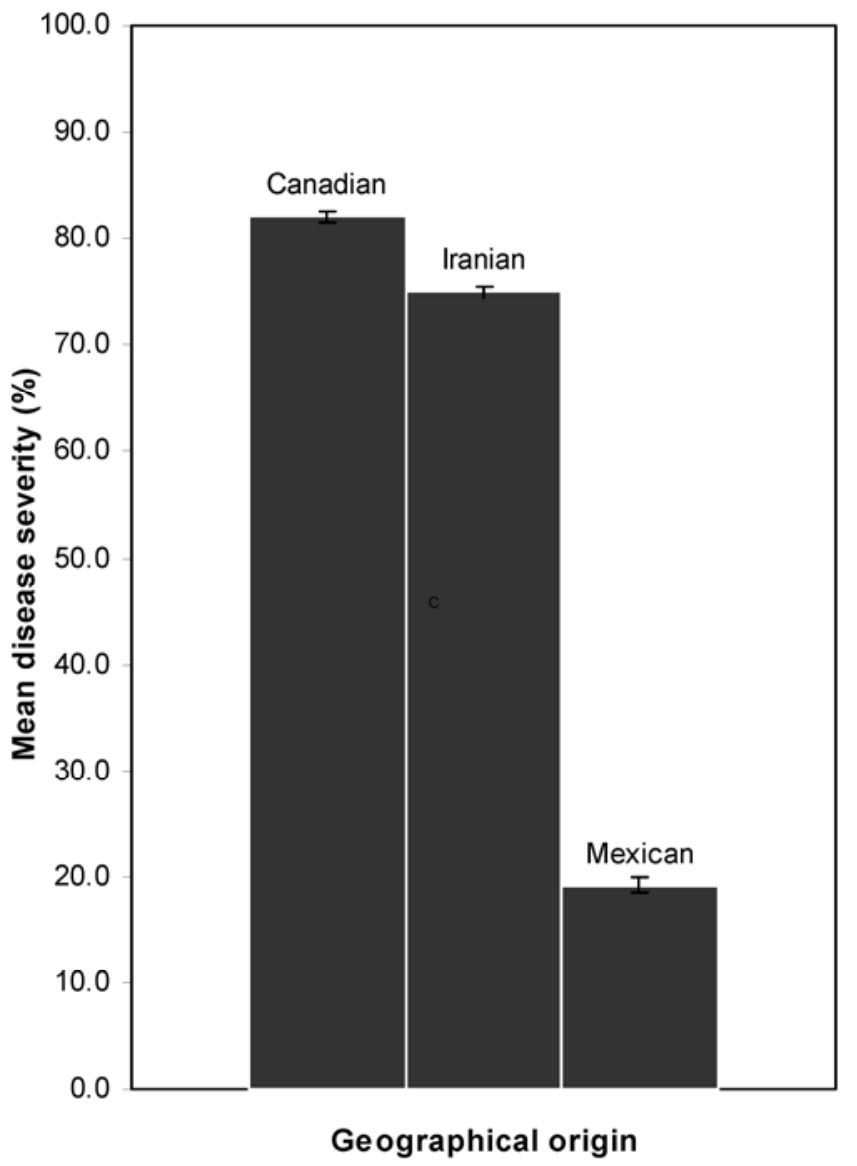

Fig. 3. Comparison of aggressiveness of Fusarium isolates from different geographical zones, measured based on percent infected spikelets (disease severity) on the susceptible cultivar Roblin, 21 days after inoculation using single-floret point inoculation. Disease severity values are back-transformed from least squares means of arcsine-transformed data. Bars on the top of each column represent the standard errors. crookwellense showed the highest to lowest aggressiveness, respectively (Fig. 4).

An association between trichothecene chemotype and aggressiveness was also observed. The NIV chemotype had the lowest $(33.5 \%)$, while the 3 -ADON chemotype had the highest mean disease severity $(87.5 \%)$. The $15-\mathrm{ADON}$ chemotype was intermediate with a mean value of $69.8 \%$ (Fig. 5). If the Mexican isolates with significantly lower disease severity values are removed, the pattern of aggressiveness from 3-ADON to 15ADON to NIV still remains the same.

\section{Discussion}

This experiment was designed and conducted to find the reason(s) for different reactions of wheat genotypes to FHB in different regions, i.e., Canada, Mexico, and Iran. To do this, phylogenetic relationships were identified, trichothecene chemotype patterns were determined, and variation in aggressiveness was assessed among 58 Fusarium isolates from different origins. In addition, the association between phylogenetic characteristics and chemotype patterns with aggressiveness was determined.

Results showed that all Canadian and Iranian isolates belonged to $F$. graminearum s.s., while the Fusarium isolates obtained from Mexico were divided into two clusters: a distinct cluster of $F$. boothii and another cluster which was identified as F. crookwellense (Fig. 1). The wide geographic distribution of $F$. graminearum s.s. isolates among the FHB pathogens examined is consistent with previous reports documenting that $F$. graminearum s.s. has a global distribution (53). F. graminearum s.s. is reported as the predominant species in Canada (K. O'Donnell, personal communication), the United States $(14,76,77)$, Argentina (59), and central Europe

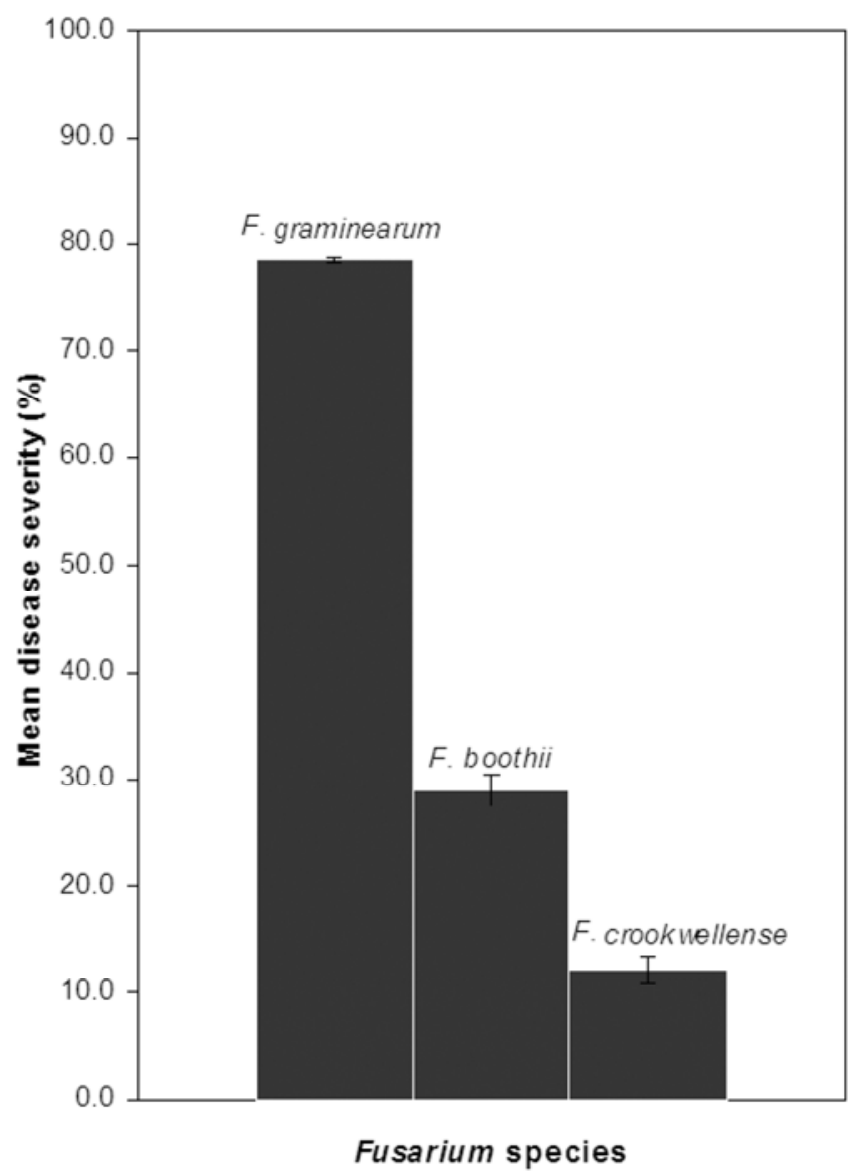

Fig. 4. Comparison of aggressiveness of different Fusarium species, measured based on percent infected spikelets (disease severity) on the susceptible cultivar Roblin, 21 days after inoculation using single-floret point inoculation. Disease severity values are back-transformed from least squares means of arcsinetransformed data. Bars on the top of each column represent the standard errors. 
(66). F. graminearum s.s. has also been detected in New Zealand (48) and several Asian countries, including China (21), Japan $(30,62)$, and Korea (33). However, F. boothii is limited to Africa, Mexico, and Mesoamerica (53). We report for the first time a phylogenetic analysis on Fusarium head blight-causing pathogens from western Asia, more specifically Iran, at a relatively extensive level. These isolates covered the predominant areas in Iran in which FHB occurs. Previously, only one isolate of Fusarium from maize from Iran was reported to be included in phylogenetic analysis, and was determined to be F. graminearum s.s. (51). F. asiaticum, which is mainly found in eastern Asia $(21,30,33,53)$, was not detected in our samples from Iran.

F. crookwellense (synonym: $F$. cerealis), a species which had previously been confused with $F$. graminearum and Fusarium culmorum (W.G. Smith) Sacc., was described as a distinct species in 1982 by Burgess, Nelson, and Toussoun $(13,49)$. Both species cause FHB in wheat and other small grain cereals. However, in contrast to $F$. boothii, $F$. crookwellense is not a species within the $\mathrm{Fg}$ clade.

Our results support the previous conclusion that the evolutionary history of NIV, 3-ADON, and 15-ADON chemotypes is different from that predicted by the species phylogeny $(51,73)$. On the other hand, any trichothecene chemotype may arise within each species. Ward et al. (73) showed that each of the trichothecene chemotypes had a single evolutionary origin in the ancestor of extant species within the $F g$ clade, and that polymorphism within these virulenceassociated genes has persisted through multiple speciation events in these fungi. They concluded that the polyphyletic distribution of trichothecene chemotypes relative to the $F g$ clade is the result of

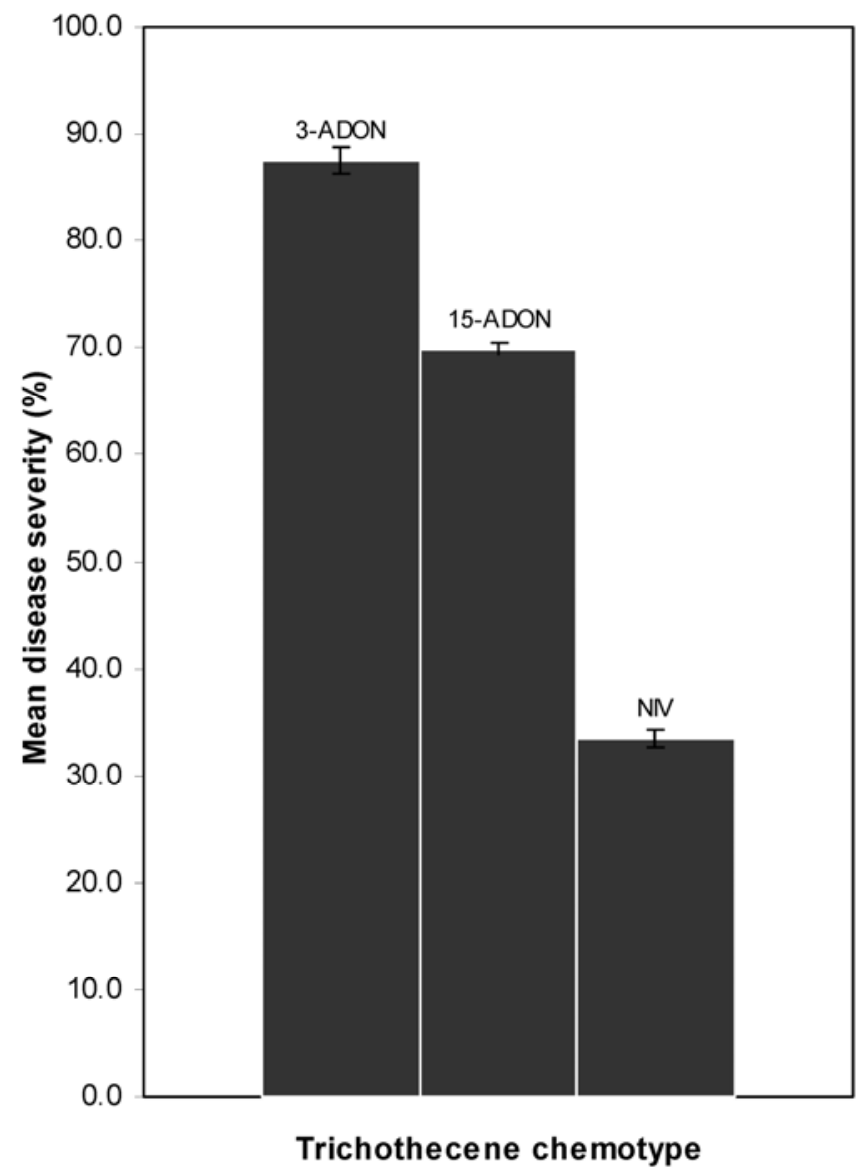

Fig. 5. Comparison of aggressiveness of Fusarium isolates with different trichothecene chemotypes, measured based on percent infected spikelets (disease severity) on the susceptible cultivar Roblin, 21 days after inoculation using singlefloret point inoculation. Disease severity values are back-transformed from least squares means of arcsine-transformed data. Bars on the top of each column represent the standard errors. trans-species evolution (73), i.e., development based on occurrence of similar alleles in related species.

The 15-ADON chemotype was predominant in this study (Fig. 1 and Table 3), which is consistent with previous reports. Earlier studies report that DON-producing isolates of $F$. graminearum occur more frequently than NIV-producing isolates, and that the $15-A D O N$ chemotype is more prevalent than the 3-ADON chemotype in many countries $(11,22,26,58,66)$. Although $F$. graminearum s.s. segregated for all three chemotypes in the present study, the predominance of a chemotype also depended on the geographic origin of the isolates. All isolates of $F$. graminearum s.s. in this study collected from Canada were determined to be DON producers, and the majority of them were identified as the 15-ADON chemotype. In contrast, the NIV chemotype was predominant among the isolates of Iran, which is in agreement with the results of Haratian et al. (27). Other studies have also revealed some regional differences among mycotoxin chemotypes $(35,45,75,78)$. More specifically, NIV isolates mostly have been reported from the eastern parts of the world, while DON chemotypes are predominant in North America (47). Such ecological differences in chemotype distribution may contribute to establish regional differences in grain contamination (58). There is also evidence of regional difference and variation in chemotype patterns among the isolates of $F$. graminearum s.s. in Iran. While all three chemotypes were detected in northern parts of the country, the isolates collected in northwestern parts were determined to be 15-ADON only. Agricultural practices and wheat cultivation system in northwestern Iran (Moghan, Ardabil) is intensive and uniform in a limited geographical zone. Therefore, there is the possibility of genetic uniformity in pathogen population in northwestern Iran. In contrast, as wheat is grown in a broader geographical area in northern parts of the country, there is the possibility of more variation in pathogen population.

While most Canadian isolates collected earlier than 1998 were determined to be 15-ADON producers, all isolates collected after 2004 were found to be of the 3-ADON chemotype (Fig. 1 and Table 1). This is in agreement with the observations that the dominant $15-\mathrm{ADON}$ FHB pathogen is being replaced by the more toxigenic population of $F$. graminearum s.s. with the 3-ADON chemotype in North America $(26,55,74)$. A significant shift from DON- to NIVproducing $F$. graminearum in northwestern Europe has also been reported (72).

While all isolates of $F$. boothii received from Mexico were identified as the 15-ADON chemotype, all F. crookwellense isolates were determined to be the NIV chemotype (Fig. 1 and Table 3 ). The major secondary metabolites produced by $F$. crookwellense, NIV-related metabolites (45), differ from those produced by $F$. graminearum (32).

Our results showed significant differences in aggressiveness of the pathogen isolates among the geographical zones (Fig. 3). The isolates collected from Canada and Iran produced higher and similar levels of disease severity on cultivar Roblin, while disease produced by the Mexican isolates was significantly lower. Analysis of data based on the Fusarium species from the same locations gives a better understanding of the results: disease severity produced by F. graminearum s.s. isolates, all collected from Canada and Iran, was significantly higher than that caused by the other species, i.e. $F$. boothii and F. crookwellense, both collected from Mexico (Fig. 4). Therefore, the difference in pathogen aggressiveness among geographical zones may be attributed to the presence of different species in different locations. We observed high variation in aggressiveness among species, with isolates of $F$. graminearum s.s. being the most aggressive, followed by $F$. boothii and F. crookwellense (Fig. 4). Even though many reports have been published on aggressiveness of Fusarium species and $F$. graminearum isolates, only a very few reports have mentioned aggressiveness in $\mathrm{F}$. graminearum phylogenetic species or the $F g$ clade. In an investigation on the isolates of Fusarium representing eight species of the $\mathrm{Fg}$ clade and three lineages of $F$. culmorum, Tóth et al. (65) found that $F$. boothii was among the least aggressive species on wheat, while 
F. graminearum s.s. isolates were the most aggressive. Alvarez et al. (2) also reported high variation in aggressiveness among $F$. graminearum s.s. isolates from Argentina.

The 3-ADON chemotype had the highest aggressiveness followed by 15-ADON and NIV chemotypes, respectively (Fig. 5). Several earlier reports also confirm that the NIV chemotype has the lowest aggressiveness $(15,25,42)$. The 3 -ADON population of $F$. graminearum found in North Dakota was also more aggressive and produced a higher level of DON in grains than the 15-ADON population in spring wheat (55). However, Ward et al. (74) and more recently, von der Ohe et al. (71) did not find significant difference between the two chemotypes in disease development. The contradiction observed in the results in different experiments may be attributed to different methods used for inoculations (55) and different environmental conditions. In spite of lack of significant differences in aggressiveness between 3-ADON and 15ADON chemotypes under spray inoculation, significant differences in DON content were observed between the two chemotypes, with higher DON produced by 3-ADON $(71,74)$. The possibility of higher production of DON by 3-ADON isolates itself is a concern, especially in susceptible wheat cultivars, particularly if the 3ADON chemotype continues to increase. Wheat genotype is another factor which may react to trichothecene chemotypes and impact pathogen aggressiveness and DON accumulation (55). While mean disease severity and trichothecene accumulation on wheat cultivars Grandin (susceptible) and ND 2710 (moderately resistant) were significantly greater for 3-ADON isolates than for 15-ADON isolates, no significant differences were observed on cultivar Steele-ND (resistant) between the two chemotypes (55). Similar results were also observed for DON accumulation by Ward et al. (74). We concluded that shifts in $F$. graminearum populations from 15-ADON to 3-ADON chemotypes may result in higher DON accumulation and/or higher FHB level in susceptible to moderately resistant wheat cultivars.

Although our results and other reports indicate an association between chemotype and aggressiveness toward wheat, it does not mean that chemotype itself is the causal factor of aggressiveness. However, trichothecene chemotypes differ in their capacity to produce DON, a factor that contributes to aggressiveness $(40,42)$. As mentioned before, in general, DON production capacity of the 3ADON chemotype is higher than other chemotypes and they are more aggressive than other chemotypes. Higher aggressiveness of 3 -ADON isolates may provide a fitness advantage over 15 -ADON isolates, as fungal growth rate, conidial reproduction, and toxin accumulation were mentioned by Ward et al. (74).

Variability in aggressiveness among isolates of a species may cause difficulties in diagnosing the disease in the field and prevent the timely application of control measures (25). The existence of high variability in the pathogen also emphasizes the need for breeders to include a wide range of isolates in their screening for selection of disease resistant varieties (25).

Genetic variation in chemotype patterns and aggressiveness was high among $F$. graminearum s.s. isolates compared to the isolates of $F$. boothii and F. crookwellense. Sources of genetic variability in these species are mutation, gene flow, and somatic recombination by heterokaryosis. Sexual recombination is also an important mechanism that changes the patterns of variation in $F$. graminearum. In addition, as the isolates of $F$. graminearum s.s. in this study were originally from diverse locations, hosts, and years (Table 1), they may originally bear diverse genetic variation. Sexual reproduction is not known for either $F$. crookwellense (45) or $F$. boothii, which may explain why these species express low levels of variation. Getting the samples from the more limited geographical area, same host, and same year, and use of smaller sample sizes for both species (Table 1) also may be mentioned.

There is no evidence for stable pathogen races in Fusarium species causing FHB $(8,41,60)$. The species of Fusarium that cause head blight in wheat can infect many other cereal crops and maize without showing specialization; a host-specific, blight-causing Fusarium species has not been documented (69). Recently, how- ever, Boutigny et al. (11) presented evidence of species-specific differences in host preferences for Fusarium species within the $\mathrm{Fg}$ clade, suggesting a close association of $F$. graminearum s.s. and $F$. boothii with wheat FHB and maize ear rot, respectively. Different species or isolates of Fusarium demonstrate high variation in their phylogenetic properties, trichothecene chemotype patterns, and pathogenicity/aggressiveness, which may greatly impact host reaction (Fig. 1). We concluded that differences in reactions of wheat lines/cultivars to FHB in different geographical zones were mainly due to differences in pathogen profile and aggressiveness. Variable environmental conditions, differences in inoculation methods, and evaluation procedures should also be considered.

Use of highly aggressive Fusarium isolates as an efficient tool for achieving adequate differentiation among host genotypes and selecting wheat genotypes with high levels of resistance to FHB is recommended in FHB nurseries and wheat breeding programs. In addition, use of a mixture of isolates of the pathogen should be preferred for artificial inoculations reflecting the conditions that occur in natural epidemics.

Resistance to FHB in wheat usually is stable, and resistant cultivars show consistent resistance to different species and isolates of Fusarium worldwide. Since the introduction of the wheat line ' $\mathrm{Su}$ mai 3' and its derivatives 30 years ago, they are still the major sources of resistance to FHB in wheat breeding programs in China $(6,36)$ and CIMMYT, Mexico (9). These sources of resistance have also been extensively tested for FHB reaction in Japan, the United States, and many European countries using a worldwide collection of $F$. graminearum isolates $(5,6,10,31,41)$. However, to assess the durability of host resistance, study of the structure of pathogen populations is very important (43). If there is a high level of genetic variation in a fungal population of an individual field, then a pathogen can rapidly adapt to the resistance genes of the host (37). Given the large genetic variability that exists in Fusarium spp., use of at least a few different resistance genes in a wheat breeding program would be a wise approach (12).

Results of the present study add to our expanding knowledge of the $F g$ complex species and support the premise that there is a relationship between the origin of the pathogen and its phylogenetic features, chemotype patterns, and aggressiveness. The results clearly showed differences among Fusarium isolates used in Mexico and the isolates from Canada and Iran. In contrast to Canada and Iran, where FHB pathogen isolates were identified as $\mathrm{F}$. graminearum s.s., the Mexican isolates belonged to the less aggressive $F$. boothii within the $F g$ clade or to $F$. crookwellense. These differences in pathogen isolates may explain, at least in part, why advanced wheat lines/cultivars that demonstrate a resistant reaction in Mexico may not express the same reaction in Canada, the United States, or other parts of the world.

In conclusion, we characterized phylogenetic relationships, chemotype patterns, and aggressiveness among Fusarium isolates from different regions, and determined the association between phylogenetic features and/or chemotype patterns with aggressiveness. In addition, we argued differences in pathogen profile and aggressiveness as one of the reasons for different reactions of wheat genotypes in different locations. Our conclusions, however, can only be considered preliminary, due to the relatively small size of the pathogen samples from different locations. The approach used in the present study can be extended to cover more geographical zones with larger sample sizes.

\section{Acknowledgments}

We thank S. M. Woods for statistical advice, K. O'Donnell for PCR primers and the $F g$ clade reference isolates and sequences, and $\mathrm{S}$. Patrick for assistance in chemotype analysis. Fusarium isolates were provided by the Cereal Research Centre, Winnipeg, Manitoba, Canada, the Seed and Plant Improvement Institute (SPII), Karaj, Iran, and the International Maize and Wheat Improvement Centre (CIMMYT), Mexico, D.F., Mexico, which are gratefully acknowledged. We also thank the following for expert technical assistance: A. Walichnowski, R. Kaethler, K Slusarenko, and U. Kromer. The Ph.D. fellowship of the first author was supported by the Agricultural Research, Education, and Extension Organization (AREEO), Ministry of Agriculture, Iran. Other expenses of this research were funded through the Cereal Research Centre (CRC), Agriculture and Agri-Food Canada. 


\section{Literature Cited}

1. Abbas, H. K., Mirocha, C. J., and Tuite, J. 1986. Natural occurrence of deoxynivalenol, 15-acetyl-deoxynivalenol, and zearalenone in refusal factor corn stored since 1972. Appl. Environ. Microbiol. 51:841-843.

2. Alvarez, C. L., Somma, S., Moretti, A., and Pinto, V. F. 2010. Aggressiveness of Fusarium graminearum sensu stricto isolates in wheat kernels in Argentina. J. Phytopathol. 158:173-181.

3. Aoki, T., and O'Donnell, K. 1999. Morphological and molecular characterization of Fusarium pseudograminearum sp. nov., formerly recognized as the group 1 population of $F$. graminearum. Mycologia 91:597-609.

4. Aoki, T., and O'Donnell, K. 1999. Morphological characterization of Gibberella coronicola sp. nov., obtained through mating experiments of Fusarium pseudograminearum. Mycoscience 40:443-453.

5. Bai, G.-H. 1995. Scab of Wheat: Epidemiology, Inheritance of Resistance, and Molecular Markers Linked to Cultivar Resistance. Purdue University, West Lafayette, IN, USA.

6. Bai, G.-H., Chen, L. F., and Shaner, G. E. 2003. Breeding for resistance to Fusarium head blight of wheat in China. Pages 296-317 in: Fusarium Head Blight of Wheat and Barley. K. J. Leonard and W. R. Bushnell, eds. American Phytopathological Society, St Paul, MN, USA.

7. Bai, G.-H., Desjardins, A. E., and Plattner, R. D. 2001. Deoxynivalenolnonproducing Fusarium graminearum causes initial infection, but does not cause disease spread in wheat spikes. Mycopathologia 153:91-98.

8. Bai, G.-H., and Shaner, G. 1996. Variation in Fusarium graminearum and cultivar resistance to wheat scab. Plant Dis. 80:975-979.

9. Bai, G.-H., and Shaner, G. E. 2004. Management and resistance in wheat and barley to Fusarium head blight. Annu. Rev. Phytopathol. 42:135-161.

10. Ban, T. 2001. Studies on the genetics of resistance to Fusarium head blight caused by Fusarium graminearum Schwabe in wheat (Triticum aestivum L.). Bull. Kyushu Natl. Agric. Exp. Stn. 38:27-78.

11. Boutigny, A. L., Ward, T. J., Coller, G. J. v., Flett, B., Lamprecht, S. C., O'Donnell, K., and Viljoen, A. 2011. Analysis of the Fusarium graminearum species complex from wheat, barley and maize in South Africa provides evidence of species-specific differences in host preference. Fungal Genet. Biol. 48:914-920.

12. Buerstmayr, H., Ban, T., and Anderson, J. A. 2009. QTL mapping and marker-assisted selection for Fusarium head blight resistance in wheat: A review. Plant Breed. 128:1-26.

13. Burgess, L. W., Nelson, P. E., and Toussoun, T. A. 1982. Characterization, geographic distribution and ecology of Fusarium crookwellense sp. nov. Trans. Br. Mycol. Soc. 79:497-505.

14. Burlakoti, R. R., Ali, S., Secor, G. A., Neate, S. M., McMullen, M. P., and Adhikari, T. B. 2008. Genetic relationships among populations of Gibberella zeae from barley, wheat, potato, and sugar beet in the upper Midwest of the United States. Phytopathology 98:969-976.

15. Cumagun, C. J. R., Bowden, R. L., Jurgenson, J. E., Leslie, J. F., and Miedaner, T. 2004. Genetic mapping of pathogenicity and aggressiveness of Gibberella zeae (Fusarium graminearum) toward wheat. Phytopathology 94:520-526.

16. Desjardins, A. E., Proctor, R. H., Bai, G., McCormick, S. P., Shaner, G., Buechley, G., and Hohn, T. M. 1996. Reduced virulence of trichothecenenonproducing mutants of Gibberella zeae in wheat field tests. Mol. PlantMicrobe Interact. 9:775-781.

17. Eudes, F., Comeau, A., Rioux, S., and Collin, J. 2001. Impact of trichothecenes on Fusarium head blight (Fusarium graminearum) development in spring wheat (Triticum aestivum). Can. J. Plant Pathol. 23:318-322.

18. Ewing, B., Hillier, L., Wendl, M. C., and Green, P. 1998. Base-calling of automated sequencer traces using phred. I. Accuracy assessment. Genome Res. 8:175-185.

19. Felsenstein, J. 1985. Confidence limits on phylogenies: An approach using the bootstrap. Evolution 39:783-791.

20. Francis, R. G., and Burgess, L. W. 1977. Characteristics of two populations of Fusarium roseum 'Graminearum' in eastern Australia. Trans. Br. Mycol. Soc. 68:421-427.

21. Gale, L. R., Chen, L. F., Hernick, C. A., Takamura, K., and Kistler, H. C. 2002. Population analysis of Fusarium graminearum from wheat fields in eastern China. Phytopathology 92:1315-1322.

22. Gale, L. R., Ward, T. J., Balmas, V., and Kistler, H. C. 2007. Population subdivision of Fusarium graminearum sensu stricto in the upper midwestern United States. Phytopathology 97:1434-1439.

23. Gardes, M., and Bruns, T. D. 1993. ITS primers with enhanced specificity for basidiomycetes - Application to the identification of mycorrhizae and rusts. Mol. Ecol. 2:113-118

24. Gilbert, J., Abramson, D., McCallum, B., and Clear, R. 2001. Comparison of Canadian Fusarium graminearum isolates for aggressiveness, vegetative compatibility, and production of ergosterol and mycotoxins. Mycopathologia 153:209-215.

25. Goswami, R. S., and Kistler, H. C. 2005. Pathogenicity and in planta mycotoxin accumulation among members of the Fusarium graminearum species complex on wheat and rice. Phytopathology 95:1397-1404.

26. Guo, X. W., Fernando, W. G. D., and Seow-Brock, H. Y. 2008. Population structure, chemotype diversity, and potential chemotype shifting of Fusarium graminearum in wheat fields of Manitoba. Plant Dis. 92:756-762.
27. Haratian, M., Sharifnabi, B., Alizadeh, A., and Safaie, N. 2008. PCR analysis of the Tril3 gene to determine the genetic potential of Fusarium graminearum isolates from Iran to produce nivalenol and deoxynivalenol. Mycopathologia 166:109-116.

28. Huang, X., and Madan, A. 1999. CAP3: A DNA sequence assembly program. Genome Res. 9:868-877.

29. Jennings, P., Coates, M. E., Walsh, K., Turner, J. A., and Nicholson, P. 2004. Determination of deoxynivalenol- and nivalenol-producing chemotypes of Fusarium graminearum isolated from wheat crops in England and Wales. Plant Pathol. 53:643-652.

30. Karugia, G. W., Suga, H., Gale, L. R., Nakajima, T., Tomimura, K., and Hyakumachi, M. 2009. Population structure of the Fusarium graminearum species complex from a single Japanese wheat field sampled in two consecutive years. Plant Dis. 93:170-174.

31. Kolb, F. L., Bai, G. H., Muehlbauer, G. J., Anderson, J. A., Smith, K. P., and Fedak, G. 2001. Host plant resistance genes for Fusarium head blight: Mapping and manipulation with molecular markers. Crop Sci. 41:611-619.

32. Lauren, D. R., Ashley, A., Blackwell, B. A., Greenhalgh, R., Miller, J. D., and Neish, G. A. 1987. Trichothecenes produced by Fusarium crookwellense Daom 193611. J. Agric. Food Chem. 35:884-889.

33. Lee, J., Chang, I.-Y., Kim, H., Yun, S.-H., Leslie, J. F., and Lee, Y.-W. 2009. Genetic diversity and fitness of Fusarium graminearum populations from rice in Korea. Appl. Environ. Microbiol. 75:3289-3295.

34. Lee, T., Han, Y.-K., Kim, K.-H., Yun, S.-H., and Lee, Y.-W. 2002. Tril3 and Tri7 determine deoxynivalenol- and nivalenol-producing chemotypes of Gibberella zeae. Appl. Environ. Microbiol. 68:2148-2154.

35. Lee, T., Oh, D.-W., Kim, H.-S., Lee, J., Kim, Y.-H., Yun, S.-H., and Lee, Y.W. 2001. Identification of deoxynivalenol- and nivalenol-producing chemotypes of Gibberella zeae by using PCR. Appl. Environ. Microbiol. 67:29662972

36. Lu, W. Z., Chen, S. H., and Wang, Y. Z. 2001. Research on Wheat Scab. Sci. Publ. House, Beijing, China.

37. McDonald, B. A., and McDermott, J. M. 1993. Population genetics of plant pathogenic fungi. BioScience 43:311-319.

38. McMullen, M., Jones, R., and Gallenberg, D. 1997. Scab of wheat and barley: A re-emerging disease of devastating impact. Plant Dis. 81:13401348 .

39. Mesterházy, A. 1984. A laboratory method to predict pathogenicity of Fusarium graminearum in the field and resistance of wheat to scab. Acta Phytopathol. Acad. Sci. Hun. 19:205-218.

40. Mesterházy, A. 2002. Role of deoxynivalenol in aggressiveness of Fusarium graminearum and F. culmorum and in resistance to Fusarium head blight. Eur. J. Plant Pathol. 108:675-684.

41. Mesterházy, A. 2003. Breeding wheat for Fusarium head blight resistance in Europe. Pages 211-240 in: Fusarium Head Blight of Wheat and Barley. K. J. Leonard and W. R. Bushnell, eds. American Phytopathological Society, St Paul, MN, USA.

42. Miedaner, T., Reinbrecht, C., and Schilling, A. G. 2000. Association among aggressiveness, fungal colonization, and mycotoxin production of 26 isolates of Fusarium graminearum in winter rye head blight. Z. Pflanzenk. Pflanzen. 107:124-134.

43. Miedaner, T., and Schilling, A. G. 1996. Genetic variation of aggressiveness in individual field populations of Fusarium graminearum and Fusarium culmorum tested on young plants of winter rye. Eur. J. Plant Pathol. 102:823-830

44. Miedaner, T., Schilling, A. G., and Geiger, H. H. 2001. Molecular genetic diversity and variation for aggressiveness in populations of Fusarium graminearum and Fusarium culmorum sampled from wheat fields in different countries. J. Phytopathol. 149:641-648.

45. Miller, J. D., Greenhalgh, R., Wang, Y., and Lu, M. 1991. Trichothecene chemotypes of three Fusarium species. Mycologia 83:121-130.

46. Miller, J. D., Taylor, A., and Greenhalgh, R. 1983. Production of deoxynivalenol and related compounds in liquid culture by Fusarium graminearum. Can. J. Microbiol. 29:1171-1178.

47. Mirocha, C. J., Abbas, H. K., Windels, C. E., and Xie, W. 1989. Variation in deoxynivalenol 15-acetyldeoxynivalenol 3-acetyldeoxynivalenol and zearalenone production by Fusarium graminearum isolates. Appl. Environ. Microbiol. 55:1315-1316.

48. Monds, R. D., Cromey, M. G., Lauren, D. R., di Menna, M., and Marshall, J. 2005. Fusarium graminearum, $F$. cortaderiae and F. pseudograminearum in New Zealand: Molecular phylogenetic analysis, mycotoxin chemotypes and co-existence of species. Mycol. Res. 109:410-420.

49. Nelson, P. E., Toussoun, T. A., and Marasas, W. F. O. 1983. Fusarium Species: An Illustrated Manual for Identification. Pennsylvania State University Press, University Park, PA, USA.

50. O'Donnell, K. 1992. Ribosomal DNA internal transcribed spacers are highly divergent in the phytopathogenic ascomycete Fusarium sambucinum (Gibberella pulicaris). Curr. Genet. 22:213-220.

51. O'Donnell, K., Kistler, H. C., Tacke, B. K., and Casper, H. H. 2000. Gene genealogies reveal global phylogeographic structure and reproductive isolation among lineages of Fusarium graminearum, the fungus causing wheat scab. PNAS 97:7905-7910.

52. O’Donnell, K., Ward, T. J., Aberra, D., Kistler, H. C., Aoki, T., Orwig, N., Kimura, M., Bjornstad, A., and Klemsdal, S. S. 2008. Multilocus genotyp- 
ing and molecular phylogenetics resolve a novel head blight pathogen within the Fusarium graminearum species complex from Ethiopia. Fungal Genet. Biol. 45:1514-1522.

53. O'Donnell, K., Ward, T. J., Geiser, D. M., Kistler, H. C., and Aoki, T. 2004. Genealogical concordance between the mating type locus and seven other nuclear genes supports formal recognition of nine phylogenetically distinct species within the Fusarium graminearum clade. Fungal Genet. Biol. 41:600-623.

54. Parry, D. W., Jenkinson, P., and McLeod, L. 1995. Fusarium ear blight (scab) in small grains-a review. Plant Pathol. 44:207-238.

55. Puri, K. D., and Zhong, S. 2010. The 3ADON population of Fusarium graminearum found in North Dakota is more aggressive and produces a higher level of DON than the prevalent $15 \mathrm{ADON}$ population in spring wheat. Phytopathology 100:1007-1014.

56. Purss, G. S. 1969. The relationship between strains of Fusarium graminearum Schwabe causing crown rot of various gramineous hosts and stalk rot of maize in Queensland. Aust. J. Agric. Res. 20:257-264.

57. Purss, G. S. 1971. Pathogenic specialization in Fusarium graminearum. Aust. J. Agric. Res. 22:553-561

58. Ramirez, M. L., Reynoso, M. M., Farnochi, M. C., and Chulze, S. 2006. Vegetative compatibility and mycotoxin chemotypes among Fusarium graminearum (Gibberella zeae) isolates from wheat in Argentina. Eur. J. Plant Pathol. 115:139-148.

59. Ramirez, M. L., Reynoso, M. M., Farnochi, M. C., Torres, A. M., Leslie, J. F., and Chulze, S. N. 2007. Population genetic structure of Gibberella zeae isolated from wheat in Argentina. Food Addit. Contam. 24:1115-1120.

60. Snijders, C. H. A., and Van Eeuwijk, F. A. 1991. Genotype $\times$ strain interactions for resistance to Fusarium head blight caused by Fusarium culmorum in winter wheat. Theor. Appl. Genet. 81:239-244.

61. Starkey, D. E., Ward, T. J., Aoki, T., Gale, L. R., Kistler, H. C., Geiser, D. M., Suga, H., Toth, B., Varga, J., and O'Donnell, K. 2007. Global molecular surveillance reveals novel Fusarium head blight species and trichothecene toxin diversity. Fungal Genet. Biol. 44:1191-1204.

62. Suga, H., Karugia, G. W., Ward, T., Gale, L. R., Tomimura, K., Nakajima, T., Miyasaka, A., Koizumi, S., Kageyama, K., and Hyakumachi, M. 2008. Molecular characterization of the Fusarium graminearum species complex in Japan. Phytopathology 98:159-166.

63. Swofford, D. L. 2003. PAUP*, phylogenetic analysis using parsimony (*and other methods). Sinauer Associates, Sunderland, MA, USA.

64. Tamura, K., Dudley, J., Nei, M., and Kumar, S. 2007. MEGA4: Molecular evolutionary genetics analysis (MEGA) software version 4.0. Pages 15961599 in: Mol. Biol. Evol.

65. Tóth, B., Kaszonyi, G., Bartok, T., Varga, J., and Mesterhazy, A. 2008. Common resistance of wheat to members of the Fusarium graminearum species complex and F. culmorum. Plant Breed. 127:1-8.

66. Tóth, B., Mesterhazy, A., Horvath, Z., Bartok, T., Varga, M., and Varga, J. 2005. Genetic variability of central European isolates of the Fusarium gra- minearum species complex. Eur. J. Plant Pathol. 113:35-45.

67. Tuite, J., Shaner, G., and Everson, R. J. 1990. Wheat scab in soft red winter wheat in Indiana USA in 1986 and its relation to some quality measurements. Plant Dis. 74:959-962.

68. Ueno, Y., Nakajima, M., Sakai, K., Ishii, K., Sato, N., and Shimada, N. 1973. Comparative toxicology of trichothecene mycotoxins inhibition of protein synthesis in animal cells. J. Biochem. 74:285-296.

69. Van Eeuwijk, F., Mesterházy, A., Kling, C. I., Ruckenbauer, P., Saur, L., Burstmayr, H., Lemmens, M., Keizer, L. C. P., Maurin, N., and Snijders, C. H. A. 1995. Assessing non-specificity of resistance in wheat to head blight caused by inoculation with European strains of Fusarium culmorum, F. graminearum and $F$. nivale using a multiplicative model for interaction. Theor. Appl. Genet. 90:221-228

70. Vanderplank, J. E. 1984. Disease Resistance of Plants. Academic Press, New York, NY, USA.

71. von der Ohe, C., Gauthier, V., Tamburic-Ilincic, L., Brule-Babel, A., Fernando, W. G. D., Clear, R., Ward, T. J., and Miedaner, T. 2010. A comparison of aggressiveness and deoxynivalenol production between Canadian Fusarium graminearum isolates with 3-acetyl and 15-acetyldeoxynivalenol chemotypes in field-grown spring wheat. Eur. J. Plant Pathol. 127:407-417.

72. Waalwijk, C., Kastelein, P., de Vries, I., Kerenyi, Z., Van der Lee, T., Hesselink, T., Kohl, J., and Kema, G. 2003. Major changes in Fusarium spp. in wheat in the Netherlands. Eur. J. Plant Pathol. 109:743-754.

73. Ward, T. J., Bielawski, J. P., Kistler, H. C., Sullivan, E., and O’Donnell, K. 2002. Ancestral polymorphism and adaptive evolution in the trichothecene mycotoxin gene cluster of phytopathogenic Fusarium. PNAS 99:92789283.

74. Ward, T. J., Clear, R. M., Rooney, A. P., O’Donnell, K., Gaba, D., Patrick S., Starkey, D. E., Gilbert, J., Geiser, D. M., and Nowicki, T. W. 2008. An adaptive evolutionary shift in Fusarium head blight pathogen populations is driving the rapid spread of more toxigenic Fusarium graminearum in North America. Fungal Genet. Biol. 45:473-484.

75. Yli-Mattila, T., Gagkaeva, T., Ward, T. J., Aoki, T., Kistler, H. C., and O'Donnell, K. 2009. A novel Asian clade within the Fusarium graminearum species complex includes a newly discovered cereal head blight pathogen from the Russian Far East. Mycologia 101:841-852.

76. Zeller, K. A., Bowden, R. L., and Leslie, J. F. 2003. Diversity of epidemic populations of Gibberella zeae from small quadrats in Kansas and North Dakota. Phytopathology 93:874-880.

77. Zeller, K. A., Bowden, R. L., and Leslie, J. F. 2004. Population differentiation and recombination in wheat scab populations of Gibberella zeae from the United States. Mol. Ecol. 13:563-571.

78. Zhang, J.-B., Li, H.-P., Dang, F.-J., Qu, B., Xu, Y.-B., Zhao, C.-S., and Liao, Y.-C. 2007. Determination of the trichothecene mycotoxin chemotypes and associated geographical distribution and phylogenetic species of the Fusarium graminearum clade from China. Mycol. Res. 111:967-975. 